\title{
Adequate fluid resuscitation decreases incidence of acute renal failure in burn patients
}

\author{
Daniel Ardian Soeselo*, **and Etheldreda Alexandria Stephanie Suparman*
}

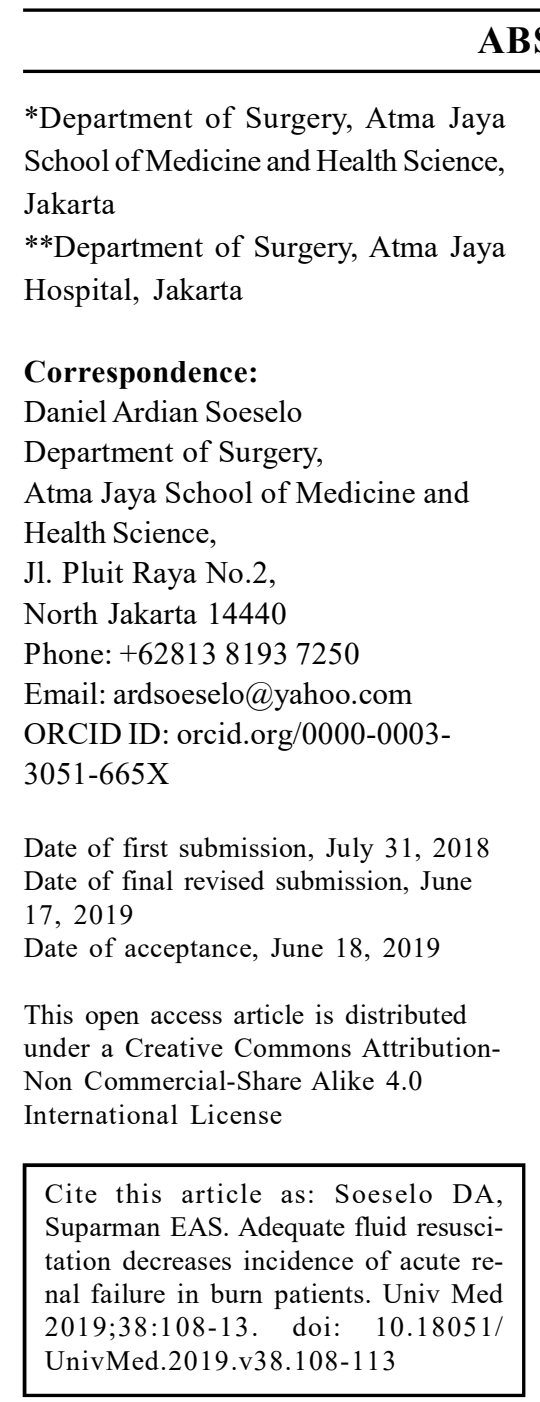

ABSTRACT

\section{BACKGROUND}

Burns constitute a severe health problem in many countries. In Indonesia burns rank 4th of all trauma-related diseases and are a burden on the country's health system. Adequate fluid resuscitation is the initial management of burns that determines the success of treatment. This study aimed to determine the relationship between adequate fluid resuscitation and incidence of acute renal failure in burn patients.

\section{METHODS}

A retrospective study of cross-sectional design was conducted on 30 burn patients who came to the Emergency Unit (ER) from January 2015-December 2017. Medical records were reviewed to examine the data on fluid resuscitation according to the Parkland formula and the laboratory data. Acute renal failure was defined as a creatinine level of more than $2.1 \mathrm{mg} / \mathrm{dL}$ after 7 days. Hypoalbuminemia was defined as an albumin level of less than $3.4 \mathrm{~g} / \mathrm{dL}$. Fisher's exact test was used to analyze the data.

\section{RESULTS}

Twenty-two subjects received fluid resuscitation according to the Parkland formula and 8 did not. Twenty-five experienced complications such as acute renal failure (ARF) (13.3\%), hypoalbuminemia (46.7\%) and a combination of ARF and hypoalbuminemia (23.3\%). One person died. Adequate fluid resuscitation was significantly associated with decrease incidence of ARF ( $p=0.015)$, but not significantly with hypoalbuminemia $(p=0.214)$ and with mortality $(p=0.267)$.

\section{CONCLUSION}

Adequate fluid resuscitation decreased the incidence of ARF in burn patients. Consensus protocols for initial burn resuscitation and treatment are crucial to avoid the consequences of ARF after burn injury.

Keywords: Burns, fluid resuscitation, acute renal failure, hypoalbuminemia, Parkland formula 


\section{INTRODUCTION}

Burns are one of the health problems in many countries, ${ }^{(1)}$ and contribute to approximately $1 \%$ of the disease burden in the world. They also cause disability in nearly 18 million persons and more than 265,000 deaths globally each year. ${ }^{(2,3)}$ More than $95 \%$ of burns occur in low-income developing countries. ${ }^{(4,5)}$ In addition, burns rank fourth of all trauma-related disorders and are also a burden for a country's health system because of the high healthcare costs as a result of prolonged hospital stays. ${ }^{(2)}$

Data from the WHO show that burns occupy ninth rank of all-cause mortality in the age group of 5-14 years, with an estimated total number of deaths of 41,575 ; and fifteenth rank in the age groups of 0-4 years and 15-29 years, with an estimated total number of deaths of 62,655 and 49,067 , respectively. ${ }^{(2,6)}$

In Indonesia, burns cause approximately 195,000 deaths each year. Cipto Mangunkusumo Hospital, as the national burn referral center in Indonesia, receives more than 130 patients each year from all over the country. According to the Indonesian Department of Health, burns occupy sixth rank as a cause of injury. ${ }^{(2)}$ Recent research on the mortality of burn patients in Cipto Mangunkusumo Hospital, Jakarta and in Soetomo Hospital, Surabaya, found that the mortality rate from burns is still high. ${ }^{(4,7,8)}$

A study on burns at Soetomo Hospital, Surabaya, in 2007-2011 showed that the maleto-female ratio of burns was $2: 1$. The most frequent cause of burns is thermal injury to a total of $48.3 \%{ }^{(8)}$ One study at the burns unit of Cipto Mangunkusumo Hospital in 2011-2012 showed that the most frequent cause was thermal injury (heat), to a total of $78 \%$, while the majority of burns are second-degree burns, with the most frequent cause of mortality being sepsis. ${ }^{(4)}$ Another study from the burns unit of Ciptomangunkusumo Hospital in 2013-2015 showed that most burn patients were $>18$ years old and that the most frequent cause was thermal injury. ${ }^{(2)}$
The study of Sanchez et al. (9) using hydroxyethyl starch found a high incidence of acute renal failure (ARF) in burn patients, as evaluated using the criteria of the risk/injury/ failure/loss/end-stage kidney (RIFLE) classification and the acute kidney injury network (AKIN). The study by Michael et al. ${ }^{(10)}$ using crystalloids showed a high incidence of ARF from inadequate resuscitation as evaluated with the RIFLE criteria, leading to a high mortality risk in burn patients. Other studies also state that one of the risk factors of ARF in burn patients is inadequate administration of rescuscitation fluid. ${ }^{(1-13)}$ The study of Kumar et al. ${ }^{(14)}$ on urea creatinine after hospitalization for 5 days states that the total amounts of crystalloid resuscitation fluid administered determine the ARF incidence in burn patients. The study by Thalji ${ }^{(15)}$ states that ARF is associated with the morbidity and mortality rates of burn patients during hospitalization and at one year post-trauma. The study of Schneider et al. ${ }^{(16)}$ using a classification and regression tree (CART) analysis and RIFLE criteria showed a high incidence of ARF in burn patients.

The difference between previous studies and the present study is that the latter describes the characteristics of burn patients who attended the Atma Jaya emergency unit (ER) Hospital and evaluated the mortality and morbidity rate by determining the presence or absence of acute kidney failure, hypoalbuminemia and death as a result of burns.

\section{METHODS}

\section{Design of the study}

This was an analytical observational crosssectional study carried out at Atma Jaya Hospital (AJH), Jakarta, by reviewing the medical records of patients hospitalized from January 2015 to December 2017.

\section{Study sample}

The study sample was obtained from the medical record data, using purposive sampling. 
The subjects in this study were all patients who came to the AJH ER within the first 24 hours after injury and who were hospitalized between January 2015 and December 2017. The exclusion criteria in this study were patients who were discharged against medical advice, patients with incomplete medical records, and patients with a history of renal failure. The formula used in calculating the sample size was $n=(Z \alpha)^{2} p q / d^{2}$ , where $Z \alpha=$ conversion area under the standard normal curve at the $96 \%$ confidence level, $\mathrm{p}=$ categorical proportion, $\mathrm{q}=1-\mathrm{p}$, and $\mathrm{d}=10 \%$ deviation (confidence interval). All patients with the diagnosis of burns were entered into this study. According to the formula the minimal sample size was 28 . A total of 40 subjects was found, but 10 subjects were excluded because of incomplete medical record data, so that in total only 30 subjects were analyzed.

\section{Definitions}

The parameter of acute kidney failure used was one of the criteria of the Kidney Disease: Global Improvement Outcome ${ }^{(17)}$ i.e. an increase in blood creatinine concentrations of 1.5 times the normal value after the $7^{\text {th }}$ day, this being $>2.1$ $\mathrm{mg} / \mathrm{dL}$. The parameter of hypoalbuminemia used was a blood albumin concentration of $<3.4 \mathrm{~g} / \mathrm{dL}$ on day 7 of hospitalization. The parameter of fluid therapy used was the agreement of the administered rescuscitation fluid with the Parkland formula, i.e. $4 \mathrm{~mL}$ x BW x \% burn area, using crystalloids. ${ }^{(18)}$

\section{Data collection}

In this study, the data obtained from the medical records were among others age, gender, and area, degree, cause, and total number of burns and type of resuscitation fluid administered, blood creatinine and albumin concentrations in the ER and at day 7 of hospitalization, and mortality data. In addition, this study evaluated the agreement with the Parkland formula of the total amount of resuscitation fluid administered $(4 \mathrm{~mL}$ x BW x $\%$ burn area) and its type (crystalloids). ${ }^{(18)}$

\section{Statistical analysis}

The statistical test used was the Kolmogorov-Smirnov test of normality to evaluate the distribution of the study data. The relationship of administered resuscitation fluid with morbidity and mortality of the burn patients was evaluated with the Fisher test.

\section{Ethical clearance}

This study obtained ethical clearance from the Ethics Commission, Faculty of Medicine, Atma Jaya Catholic University of Indonesia, Jakarta, under No. 02/06/KEP-FKUAJ/2018.

\section{RESULTS}

The characteristics of burn patients at $\mathrm{AJH}$ (Table 1) showed that the majority were males, to a total of 18 persons $(60 \%)$. The most frequent age group, according to the World Health Organization (WHO) classification, was the age group of 18 - 65 years, totalling 27 persons (90\%). The largest burn area (as percentage of total body surface) was 21-49\%, totalling 19 persons (63.4\%). The most frequent degree of burn was IIA with a total of 18 persons $(60 \%)$. The most frequent cause of burns was heat, with a total of 28 persons $(93.3 \%)$. The percentage of burn patients who received resuscitation according to reference was $73.3 \%$. The number of morbidity events in the form of ARF and hypoalbuminemia was found to be 25 . Four persons $(13.3 \%)$ had ARF only, 14 persons $(46.7 \%)$ had hypoalbuminemia only, and 7 persons $(23.3 \%)$ had ARF and hypoalbuminemia. One person died after administration of resuscitation fluid and hospitalization for 22 days as a result of hospitalacquired pneumonia (Table 1).

Analysis of the association between resuscitation fluid and morbidity of burn patients in AJH was performed with Fisher's test. The morbidity of burn patients in this study was divided into two, i.e. due to ARF and hypoalbuminemia. Analysis of the association of ARF with resuscitation fluid in burn patients found a $p$ value of $0.015(p<0.05)$, so that there was a significant 
Table 1. Distribution of characteristics of burn patients $(n=30)$

\begin{tabular}{|c|c|c|c|}
\hline & & \multicolumn{2}{|c|}{ Total } \\
\hline & & $\mathbf{n}$ & $\%$ \\
\hline \multirow[t]{2}{*}{ Gender } & Male & 18 & 60 \\
\hline & Female & 12 & 40 \\
\hline \multirow[t]{4}{*}{ Age } & $\leq 17$ years & 2 & 6.7 \\
\hline & $18-65$ years & 27 & 90 \\
\hline & $66-79$ years & 1 & 3.3 \\
\hline & $\geq 80$ years & 0 & 0 \\
\hline \multirow[t]{3}{*}{ Burn area } & $\leq 20 \%$ & 5 & 16.7 \\
\hline & $21-49 \%$ & 19 & 63.3 \\
\hline & $\geq 50 \%$ & 6 & 20 \\
\hline \multirow[t]{4}{*}{ Degree of burn } & Grade I & 0 & 0 \\
\hline & Grade II A & 18 & 60 \\
\hline & Grade II B & 11 & 36.7 \\
\hline & Grade III & 1 & 3.3 \\
\hline \multirow{3}{*}{ Cause of burn } & Thermal & 28 & 93.3 \\
\hline & Electrical & 1 & 3.3 \\
\hline & Chemical & 1 & 3.3 \\
\hline \multirow[t]{2}{*}{ Agreement of fluid therapy } & Yes & 22 & 73.3 \\
\hline & No & 8 & 26.7 \\
\hline \multirow[t]{4}{*}{ Morbidity } & None & 5 & 16.7 \\
\hline & Acute renal failure & 4 & 13.3 \\
\hline & Hypoalbuminemia & 14 & 46.7 \\
\hline & Acute renal failure + hypoalbuminemia & 7 & 23.3 \\
\hline \multirow[t]{2}{*}{ Mortality } & Live & 29 & 96.7 \\
\hline & Dead & 1 & 3.3 \\
\hline
\end{tabular}

association between adequate administration of resuscitation fluid and decrease in ARF incidence. In the analysis of the association of hypoalbuminemia with resuscitation fluid in burn patients, a non-significant association was found $(p=0.214)$ (Table 2). Analysis of the association between resuscitation and mortality of burn patients found a non-significant association between administration of resuscitation fluid and incidence of mortality of burn patients $(\mathrm{p}=0.267)$ (Table 2).

\section{DISCUSSION}

This study showed that the most frequent gender was male, in a male-to-female ratio of $1.5: 1$. A study in the last 5 years stated that the most frequent cases of burns were in males as compared with females. This is due to the greater mobility and activity of males as compared to females. ${ }^{(8)}$ A study carried out at RSCM also found a predominance of males as compared to females in burn cases. ${ }^{(2)}$

Table 2. Analysis of the association of resuscitation fluid with ARF incidence, hypoalbuminemia and mortality of burn patients $(n=30)$

\begin{tabular}{llccc}
\hline & & \multicolumn{2}{c}{ Resuscitation } & \multirow{2}{*}{ p value } \\
\cline { 3 - 4 } & & In agreement (n) & Not in agreement (n) & \multirow{2}{*}{0.028} \\
\hline ARF & Yes & 5 & 6 & \\
\multirow{3}{*}{ Hypoalbuminemia } & No & 17 & 2 & 0.374 \\
\multirow{3}{*}{ Mortality } & Yes & 14 & 7 & \\
& No & 8 & 1 & 0.267 \\
& Live & 22 & 7 & 1 \\
\hline
\end{tabular}

ARF: acute renal failure 
In the present study, the highest number of burn cases was in the age group of 18 - 65 years ( $90 \%$ of 27 cases). This is in agreement with existing research data on the age of burn patients, showing that these mostly occur in the first to the fifth decade of life. ${ }^{(2,8)}$ These age groups are the productive age groups, whose members are working and more frequently exposed to hazardous situations, so that the incidence of burns is highest in the productive age $(68 \%){ }^{(2)}$ The study results show that the number of burn cases occurring in the age interval of 18-65 years was in total 27 (90\%). The highest age of the burn cases in this study was 65 years (one case) and the youngest age was 6 years (one case).

The study results show that the most frequent burn area was $\leq 20 \%$, with 5 cases (16.7\%). This differs from the study carried out at RSCM where the burn area was $20-50 \% .^{(2,8)}$ In our opinion, this is due to a difference in hospital type. RSCM is the reference burns centre, so that the burn cases managed over there are certainly more complicated and severe.

The study results show that the most frequent cause of burns was heat, with a total of 28 cases (93\%). This is in line with the study carried out at RSCM where the most frequent cause of burns was heat (due to explosion of LPG bottles). ${ }^{(2,7)}$

Fluid resuscitation therapy in burn patients is varied. In this study we used the Parkland formula as reference and found that 22 patients $(73.3 \%)$ received therapy according to the Parkland formula. This formula, even if appropriately applied, still has several limitations, such as errors in determining body weight, burn degree, and burn area. These errors may result in the over- or underestimation of the total amount of fluid actually required by the patients.

This study found a significant association between adequate administration of resuscitation fluid and decreased incidence of ARF. This is in line with the results of other studies, stating that adequate administration of resuscitation fluid may prevent ARF, by improving tissue perfusion, particularly in the kidneys. ${ }^{(16,19,20)}$ Adequate administration of resuscitation fluid to burn patients may maintain the homeostatic balance in the blood vessels and tissue perfusion.

This study found no significant association between administration of resuscitation fluid according to the Parkland formula and incidence of hypoalbuminemia. This is in line with other studies stating that even adequate administration of resuscitation fluid may still cause hypoalbuminemia, as seen from the serum albumin concentration. ${ }^{(20)}$ In addition, this is also one of the pathophysiological mechanisms of burns, where vasodilation of the blood vessels is still present, even after adequate administration of resuscitation fluid. This causes extravasation of protein and albumin as a result of capillary permeability. ${ }^{(21)}$

A limitation of this study was that it was not designed to demonstrate the effectiveness and safety of fluid administration according to the Parkland formula and therefore had no control group. In addition, this study comprised many confounding factors, so that a larger number of patients would be needed to draw appropriate conclusions. The clinical impact of the findings of this study is that administration of fluid according to the Parkland formula may avoid ARF in burn patients. Further research is expected to involve prospective studies with a larger sample size.

\section{CONCLUSIONS}

Adequate administration of resuscitation fluid may reduce ARF incidence in burn patients. Although the Parkland formula may prevent ARF, it has several limitations in its application. There is a need for strict supervision during fluid resuscitation, even when the Parkland formula is used.

\section{CONFLICT OF INTEREST}

There is no conflict of interest in this study. 


\section{ACKNOWLEDGEMENT}

The authors wish to thank all staff members in the medical record section who provided the medical records of burn patients in Atma Jaya Hospital, Jakarta.

\section{CONTRIBUTORS}

DAS dan EASS contributed to composing and writing all manuscript drafts. All authors contributed information for the manuscript, participated in revising the manuscript, and approved the final version for publication.

\section{REFERENCES}

1. Yasti AC, Senel E, Saydam M, et al. Guideline and treatment algorithm for burn injuries. Turk J Trauma Emerg Surg 2015;21:79-89. doi: 10.5505/ tjtes.2015.88261.

2. Wardhana A, Basuki A, Prameswara ADH, et al. The epidemiology of burns in Indonesia's national referral burn center from 2013 to 2015 . Burns Open 2017;1:67-73. DOI: https://doi.org/ 10.1016/j.burnso.2017.08.002.

3. World Health Organization. Global health estimates 2016: disease burden by cause, age, sex, by country and by region, 2000-2016. Geneva: World Health Organization; 2018.

4. Martina NR, Wardhana A. Mortality analysis of adult burn patients. J Plast Rekonstr 2013;2:497524. DOI: https://doi.org/10.14228/155.

5. Van der Merwe AE, Steenkamp WC. Prevention of burns in developing countries. Ann Burns Fire Disasters 2012;25:188-91.

6. World Health Organzation. WHO health estimates 2014 summary tables: deaths and global burden of disease. Geneva: World Health Organzation; 2014.

7. Pujisriyani, Wardana A. Epidemiology of burn Injuries in Cipto Mangunkusumo Hospital from 2009 to 2010. J Plast Rekonstruksi 2012;1:528-31. DOI: https://doi.org/10.14228/110.

8. Hidayat TSN, Noer MS. Five years retrospective study of burns in Dr. Soetomo General Hospital Surabaya. J Rekonstr Estet 2013;1:123-30.

9. Sánchez-Sánchez M, Garcia-de-Lorenzo A, Cachafeiro L, et al. Acute kidney injury in critically burned patients resuscitated with a protocol that includes low doses of hydroxyethyl starch. Ann Burns Fire Disasters 2016; 29:183-8.
10. Michael J, Tam N, Matthew B, et al. Early acute kidney injury predicts progressive renal dysfunction and higher mortality in severely burned adults. J Burn Care Res 2010;31:83-92. doi: 10.1097/BCR.0b013e3181cb8c87.

11. Wu G, Xiao Y, Wang C, et al. Risk factors for acute kidney injury in patients with burn injury: a metaanalysis and systematic review. J Burn Care Res 2017;38:271-82. doi: 10.1097/BCR.0000000000 000438 .

12. Clark A, Neyra J, Madni T, et al. Acute kidney injury after burn. Burns 2017;43:898-908. DOI: https://doi.org/10.1016/j.burns.2017.01.023.

13. Coca SG, Bauling P, Schifftner T, et al. Contribution of acute kidney injury toward morbidity and mortality in burns: a contemporary analysis. Am J Kidney Dis 2008;49:517-23.

14. Kumar AB, Andrews W, Shi Y, et al. Fluid resuscitation mediates the association between inhalational burn injury and acute kidney injury in the major burn population. J Crit Care 2017;38:62-67. doi: 10.1016/j.jcrc.2016.10.008.

15. Thalji SZ, Kothari AN, Kuo PC, et al. Acute kidney injury in burn patients: clinically significant over the initial hospitalization and 1 year after injury: an original retrospective cohort study. Ann Surg 2017;266:376-82. doi: 10.1097/SLA.000000000000 1979.

16. Schneider DF, Dobrowolsky A, Shakir IA, et al. Predicting acute kidney injury among burn patients in the 21 st century: a classification and regression tree analysis. J Burn Care Res 2012; 33:242-51. doi: 10.1097/BCR.0b013e318239cc24.

17. International Society of Nephrology. Guidelines - KDIGO. Kidney disease improving global outcomes (KDIGO). Kidney International Supplements 2017;7:1-59.

18. Wardhana A, Hardya H, Rezza M. Parkland formula vs restricted fluid in burn resucitation a systematic review of cohort studies. Critical Care Med 2018;46:34. doi: 10.1097/01.ccm.0000528323. 46970.09 .

19. Watkins SC, Shaw AD. Fluid resuscitation for acute kidney injury: an empty promise. Curr Opin Crit Care 2016;22:527-32. doi: 10.1097/MCC. 0000000000000363.

20. Pérez-Guisado J, de Haro-Padilla JM, Rioja LF, et al. Serum albumin levels in burn people are associated to the total body surface burned and the length of hospital stay but not to the initiation of the oral/enteral nutrition. Int J Burns Trauma 2013;3:159-63.

21. Becerra OAA, Garibay CT, Amezcua MDM, et al. Serum albumin level as a risk factor for mortality in burn patients. Clinics (Sao Paulo) 2013;68:9405. doi: 10.6061/clinics/2013(07)09. 